\title{
Incidence, risk factors and treatment outcomes of drug extravasation in pediatric patients in China
}

\author{
Ya-Min Yan, Mei Gong, Jia-Ling Chen, Dan Li, Ting-Ting Xu, Huan Zou, Ai-Qiu Li, \\ Qiao-Ling Fan, Qun-Feng Lu \\ Pediatric Intensive Care Unit, Shanghai Children's Hospital, Shanghai Jiao Tong University, Shanghai, China. \\ E-mail:littlegrass1987@hotmail.com \\ Received: 22nd November 2016, Revised: 14th February 2017, Accepted: 20th February 2017
}

\begin{abstract}
SUMMARY: Yan YM, Gong M, Chen JL, Li D, Xu TT, Zou H, Li AQ, Fan QL, $\mathrm{Lu} \mathrm{QF}$. Incidence, risk factors and treatment outcomes of drug extravasation in pediatric patients in China. Turk J Pediatr 2017; 59: 162-168.

Extravasation injury is a common phenomenon in hospitals. Failure to detect and treat extravasation injury can lead to irreversible local injuries, tissue necrosis and malfunction of the affected tissue. Until now, it is largely unknown about incidence, risk factors and treatment outcomes of extravasation in Chinese pediatric patients. The aim of this study is to explore the incidence, risk factors and summarize the characteristics and treatment outcomes of extravasation injuries resulting in drug extravasation among Chinese children in our hospital. The children undergoing infusion therapy (0-18 years) were enrolled in this study between December 2014 and June 2015 in Shanghai Children's Hospital. The patients' information including age, gender, injection site, estimated volume of solution extravasated, patient symptoms, severity of extravasation injury, treatment methods, and outcomes was collected. Multivariate logistic regression was used to identify the independent risk factors for the development of extravasation. The incidence of extravasations in pediatric patients was $1.79 \%(18 / 1,004)$. The severity of extravasation was labeled with grade range from Grade 1 through Grade 4: 4 cases with Grade 1, 8 cases with Grade 2, 5 cases with Grade 3, and 1 case with Grade 4 . The risk factors of extravasation include infused high volume/day $(\geq 1000 \mathrm{ml})$, received operation, infused agents with high osmolarity and poor vein condition. The severity of extravasation was related to the large volumes of drug or special drugs (high-osmolarity, high-risk, low $\mathrm{pH}$, etc). All extravasations were treated with physical, pharmacological and surgical intervention according to our standard operation protocols. Systematic implementation of intervention can alleviate the extravasation injuries and improve the patients' outcome.
\end{abstract}

Key words: infusion therapy, drug, extravasation, pediatric patients.

Infusion therapy is commonly used in hospitals, especially in the inpatients who received operation or with severe malfunction. Extravasation, the unexpected leakage of infused solution into surrounding tissue, is known as a common complication of infusion therapy, and can lead to severe injuries without intervention timely ${ }^{1,2}$. Because of more movement, lack of communication skill, small and fragile veins, capillary leakage, flexible subcutaneous tissue, the pediatric patients are more susceptible to extravasation injuries than adults ${ }^{3}$, especially in the neonates. According to the report, the incidence of extravasations from Teflon ${ }^{\circledR}$ catheters is varied from $23 \%$ to $63 \%^{4}$, and the gestational age is significantly related to the incidence of skin necrosis, the highest injuries was recorded in extremely preterm infants of 27 weeks of gestation or less 5 . Failure to detect and treat extravasation injuries can lead to tissue necrosis and malfunction of the affected tissue $^{6}$. Furthermore, it often leads to prolonged care and hospital stay, secondary infection and high morbidity in neonates 7,8 . It indicated that the preterm and low-birth weight infants are more likely to experience skin necrosis when extravasation happened. 
Extravasation can induce varying degrees of localized skin injury and cause pain, swelling, infection, or even full-thickness necrosis, and malfunction or amputation. The symptoms of the injury and the management plans depend on the cytotoxicity and volume of extravasated agent, the disease condition of the patients, and the necrosis interval of the injury ${ }^{9-11}$. It is important to identify risk factors for reducing the incidence of intravenous extravasation ${ }^{12}$. Accumulated evidences have explored the risk factors of extravasation in neonates or adults. However, it is still unknown about the incidence, risk factors and treatment outcomes of extravasation in pediatric patients in China.

Therefore, the aim of the present study is to explore the incidence, risk factors of extravasation and to summarize the treatment outcomes of drug extravasation in pediatric patients in China.

\section{Methods}

\section{Setting and sample}

This study was conducted in Shanghai Children's Hospital, which received 0-18 years old children. A retrospective analysis of total 1,004 inpatients' medical records was performed between December 2014 and June 2015. All medical records were screened in detail for parameters including age, gender, injection site, symptoms, estimated volume of drug extravasated, patient symptoms, severity of extravasation injury, treatment methods, and outcomes. The severity of extravasation injuries was graded according to the previous reports 5,13 (Table I), and the vein condition was assessed according to the standards of our hospital ${ }^{14}$.

There are standardized protocols for venous catheterization: 1.The doctor determines whether to establish venous access or not; 2.The registered nurse performs IV catheterization; 3 . If the registered nurse fails to perform IV catheterization at the first attempt, an evaluation should be made to determine whether to change another nurse; if two attempts are failure, members of the vein management group should be called to rescue vascular access. When venous access is difficult to establish, physicians should reevaluate the need for an IV line and consider alternatives of IV therapy or IV lines ${ }^{14}$. After successful catheterization, the registered nurse is responsible for the management of venous access in infusion process. If extravasation happens, the enterostomal therapist and members of vein management group should be called to evaluate the injury and implement interventions. If surgical intervention is needed, surgeon should be called to rescue the injury.

\section{Patient treatment}

All pediatric patients with extravasation subsequently received physical, pharmacological or surgical intervention according to standards of Shanghai Children's Hospital. Physical intervention includes cold/warm compress, elevation, saline dressing, foam dressing mepilex, silver ion alginate dressing. Pharmacological intervention includes injected with hyaluronidase/ phentolamine, massaged with hirudoid, etc. The choice of the intervention methods depends on the results of evaluation on the injuries made by members of vein management group and physicians. All parents or guardians of pediatric patients provided written informed consent for the therapy. Given this was a retrospective study, informed consent for the study was waived. This study was approved by the Ethics Committee of Shanghai Children's Hospital (Decision no. 2015R027-F01).

\section{Statistical analyses}

Data were analyzed using SPSS 16.0 (SPSS Inc., Chicago, IL). Continuous variables were summarized as means \pm standard derivations (SD) for normal distribution data and as median (Inter Quartile Range) for abnormal distribution data. Student $t$ test was used to compare the means of continuous variables and normally distributed data; otherwise, the Mann-Whitney $U$ test was used. Categorical variables were presented as numbers and percentages, and Chi square test or Fisher's exact test was used to compare the categorical data. Multivariate logistic regression was performed to identify the risk factors of extravasation. The adjusted odds ratios (ORs) with 95\% confidence intervals (CI) were reported. A value of $P<0.05$ was considered statistically significant.

\section{Results}

\section{Patient characteristics}

From December 2014 to June 2015, a total of 1,004 inpatients receiving infusion therapy 
Table I. The Grading of Extravasation Injuries.

\begin{tabular}{llll}
\hline Grade 1 & Grade 2 & Grade 3 & Grade 4 \\
\hline Pain & Pain & Pain & Pain \\
& Swelling & Swelling & Swelling \\
& No skin blanching & Skin blanching & Skin blanching \\
& Normal capillary refill and & Cool blanched area & Cool blanched area \\
& Normal capillary refill and & Reduced capillary refill \\
& peripheral pulsation & peripheral pulsation & + /- Arterial occlusion \\
& & $+/$ - Blistering \\
\hline
\end{tabular}

Table II. Characteristics of 18 Patients with Extravasation.

\begin{tabular}{ll}
\hline Characteristics & Results \\
\hline Patients' age & $3.31 \pm 3.29$ years \\
Male/female, n (\%) & $10(55.56) / 8 \quad(44.44)$ \\
Extravasation site, $\mathrm{n}(\%)$ & $11(61.1)$ \\
$\quad$ dorsum of hand & $4(22.2)$ \\
dorsum of foot & $2(11.1)$ \\
saphenous & $1(5.6)$ \\
forearm & $2(11.1)$ \\
Vein condition level, n (\%) & $3(16.7)$ \\
0 & $5(27.8)$ \\
I & $8(44.4)$ \\
II & $1(5.6)$ \\
Infused total volume per day(ml) & $4(22.2)$ \\
$\leq 100$ & $10(55.6)$ \\
$100 \sim 500$ & $3(16.7)$ \\
$500 \sim 1000$ & $8(44.4)$ \\
$\geq 1000$ & $7(38.9)$ \\
Estimated amount of extravasated agents & $2(11.1)$ \\
$\leq 10$ ml & $1(5.6)$ \\
$10 \sim 20$ ml & $4(22.2)$ \\
$\geq 20$ ml & $8(44.4)$ \\
Not estimated & $5(27.8)$ \\
Grade, $\mathrm{n}$ (\%) & $1(5.6)$ \\
2 &
\end{tabular}

in Shanghai Children's Hospital enrolled in this study, and 18 patients experienced drug extravasation. Mean age of the patients (10 male and 8 female) was $3.31 \pm 3.29$ years (range, 9 months -16 years). The involved extravasation site included dorsum of hand (11), dorsum of foot (4), saphenous (2) and forearm (1). The severity of extravasation was Grades 1 in 4 patients, Grade 2 in 8 patients, Grade 3 in 5 patients and Grade 4 in 1 patient, respectively (Table II).

\section{Incidence and risk factors of extravasation}

Among the 1,004 patients, drug extravasation occurred in $18(1.79 \%)$ patients. All the patients complained of pain, discomfort at the site of infusion and displayed with crying, which led to the detection of extravasation in these patients. An infusion pump alarm was another lead to find extravasation in 1 patient. In the remaining 5 patients, a nurse detected extravasation during her round of visits. The clinical characteristics were compared between the pediatric patients with or without extravasation to evaluate the risk factors for extravasation. This comparison showed significant differences in 7 factors, including infused large volume mediation ( $\geq 1000 \mathrm{ml} /$ day), infused agents with high osmolarity, received operation, poor 
Table III. Independent Risk Factors for Extravasation.

\begin{tabular}{lllll}
\hline Variable & $\mathrm{B}$ & $\mathrm{OR}$ & $95 \% \mathrm{CI}$ & $\mathrm{P}$ value \\
\hline Infused total volume (ml)/day & 0 & 1.000 & $1.000-1.001$ & 0.043 \\
Received operation & 1.673 & 5.328 & $1.383-20.526$ & 0.015 \\
Agents with high osmolarity & 1.752 & 5.768 & $1.492-22.304$ & 0.011 \\
Vein level (level 0. I. II. III) & -1.363 & 0.256 & $0.087-0.754$ & 0.013 \\
\hline
\end{tabular}

Table IV. Symptoms and Treatment of Patients with Extravasation.

\begin{tabular}{|c|c|c|c|c|}
\hline $\begin{array}{l}\text { Patients' } \\
\text { No. }\end{array}$ & $\begin{array}{l}\text { Age } \\
\text { (years) }\end{array}$ & Symptoms & Treatment & $\begin{array}{l}\text { Follow-up } \\
\text { duration }\end{array}$ \\
\hline 1 & 6.00 & Pain on the infusion site & Cold compress & 1 week \\
\hline $2-4$ & $0.69 \pm 0.34$ & Pain with motion & Cold compress, elevation & 2 weeks \\
\hline $5-7$ & $1.94 \pm 1.08$ & $\begin{array}{l}\text { Pain with motion, mild } \\
\text { swelling }\end{array}$ & $\begin{array}{l}\text { Cold compress, elevation, } \\
\text { massaged with hirudoid }\end{array}$ & 1 month \\
\hline $8-12$ & $5.20 \pm 3.97$ & $\begin{array}{l}\text { Pain with motion, mild } \\
\text { swelling, skin blanching, } \\
\text { firmness }\end{array}$ & $\begin{array}{l}\text { Cold compress, elevation, } \\
\text { massaged with hirudoid, } \\
\text { compressed with } 10 \% \mathrm{NaCl}\end{array}$ & 2 months \\
\hline $\begin{array}{l}13-14, \\
16\end{array}$ & $0.69 \pm 0.53$ & $\begin{array}{l}\text { Pain with motion, swelling, } \\
\text { skin blanching, firmness, } \\
\text { small skin erythema }\end{array}$ & $\begin{array}{l}\text { Cold compress, elevation, } \\
\text { massaged with hirudoid, injected } \\
\text { with hyaluronidase }\end{array}$ & 2 months \\
\hline 15,17 & $3.00 \pm 1.41$ & $\begin{array}{l}\text { Pain with motion, apparent } \\
\text { swelling, cool blanched } \\
\text { area, skin erythema }\end{array}$ & $\begin{array}{l}\text { Warm compress, elevation, } \\
\text { massaged with hirudoid, injected } \\
\text { with hyaluronidase, saline } \\
\text { dressing }\end{array}$ & 3 months \\
\hline 18 & 2.00 & $\begin{array}{l}\text { Pain, apparent swelling, } \\
\text { reduced capillary refill, } \\
\text { inflammation, tissue death } \\
\text { and necrosis }\end{array}$ & $\begin{array}{l}\text { Massaged with hirudoid, injected } \\
\text { with hyaluronidase, saline } \\
\text { dressing, foam dressing mepilex, } \\
\text { silver ion alginate dressing, } \\
\text { surgical excision }\end{array}$ & 5 months \\
\hline
\end{tabular}

venous condition, received chemotherapy, junior nurse and nurse without systematic training. Multivariable logistic analysis was performed with these variables. The independent risk factors of extravasation included poor condition of vein $(\mathrm{OR}=0.256,95 \% \mathrm{CI}: 0.087-0.754, \mathrm{P}$ $=0.013)$, received operation $(\mathrm{OR}=5.328,95 \%$ CI: 1.383-20.526, $\mathrm{P}=0.015)$, infused agents with high osmolarity $(\mathrm{OR}=5.768,95 \% \mathrm{CI}$ : 1.492-22.304, $\mathrm{P}=0.011)$ and infused large volume agents $(\geq 1000 \mathrm{ml} / \mathrm{d})(\mathrm{OR}=1.000,95 \%$ CI: 1.000-1.001, P = 0.043) (Table III).

\section{Symptoms and treatments}

The most commonly reported symptoms in the patients were swelling (17/94.44\%) and pain (11/ 61.11\%). Other symptoms included skin blanching in 3 patients (16.67\%), skin erythema in 2 patients $(11.11 \%)$, cool blanched area and reduced capillary refill in 1 patient $(5.56 \%)$.
Most patients were treated with cold compresses or ice packs, and elevating the involved limb. Other treatment measures included compressed with $10 \% \mathrm{Nacl}$, massaged with hirudoid, injected with hyaluronidase, etc. The patient (Case 18) with grade 4 extravasation injury received surgical intervention (Table IV).

\section{Discussion}

Although extravasation associated with infusion therapy is well recognized, there is few detailed research report on the incidence, risk factors and treatment outcomes of extravasation in Chinese pediatric patients. In the present study, the incidence of extravasation in Chinese children was $1.79 \%$ (18 of 1004 patients), which is higher than the reported results between $0.03 \%$ and $0.90 \% 9,15-17$. However, the incidence of extravasation is as high as $44.13 \%$ in the case series with small simple size $^{18}$. In this study, $33.3 \%$ (6 of 18 patients) 
experienced severe extravasation, and $5.6 \%$ (1 of 18 patients) experienced skin necrosis (Case 18). Although most extravasation can be prevented with careful administration techniques or diagnostic test ${ }^{19}, 20$, extravasation still occurs every day. Fortunately, there is now greater knowledge about how extravasations occur and affect the tissue, and how they may be effectively treated ${ }^{21}$.

In the present study, only one case $(1 / 18)$ received surgical intervention, which was benefit from early detection with a small amount of agents leaking into the perivenous tissues. Most cases with estimated amount of extravasated agents were less than $20 \mathrm{ml}$, which is also an important factor that influenced the patients' outcome.

There are multiple risk factors for developing an extravasation injury, including patientrelated factors ${ }^{22}, 23$, previous insertion in the same limb ${ }^{24}$, and the injected drug 22 . The results of this study showed that infused high volume/day, received operation, infused agents with high osmolarity and poor vein condition increased the risk of extravasation (all $p<$ 0.05). However, catheter-related factors and staff-related factors were not independent risk factors for developing an extravasation (all $p>0.05$ ). In this study, extravasation was associated with a higher infusion volume of above $1000 \mathrm{ml}$ per day. Furthermore, the children always cried and moved because of pain and uncomfortable after operation, and we found that the extravasation occurred in one-third of patients who received operation, which suggests that patient movement is a welldescribed risk factor for extravasation. Thus, fixing the needles and instructing patients after operation or received high osmolarity agents could be improved. Specifically in regard to the performer, choice of the insertion site, the insertion ability, detection and management ability are important. However, information on the staffs' level of peripheral venous management could not be evaluated precisely.

In this study, the most commonly reported symptoms in the patients were swelling (94.44\%) and pain $(61.11 \%)$, which is supported by other reports ${ }^{6,8}$. Reduced capillary refill, inflammation, and tissue necrosis appeared in 1 case $(5.56 \%)$, mostly because total parenteral nutrition (TPN) extravasated and without timely detected and intervention, which is a common reason for induced injuries in neonates ${ }^{25}$. All the complaints of symptoms associated with extravasation, so education and training of nursing and medical staff is important in prevention and early detection of extravasation injuries.

In order to alleviate the symptom and avoid additional complication, every effort should be made to minimize the extravasation injuries ${ }^{19}$. Towards suspected extravasation, medical emergencies also should be approached systematically. There were $18(1.79 \%)$ cases of extravasation in this study, and all the patients with extravasation were treated according to our standards resulting in clinical benefit. To simplify the strategy for treatment options, we summarized our therapy in physical intervention, pharmacological intervention and surgical intervention. There were 2 patients (Case 15, 17) informed about the potential need for surgery. However, both of them (Case $15,17)$ received the conservative treatment resulting in good outcomes. This result is consistent with previous study and suggested that providing intervention within the golden time ( 8 hours, 3 hours for high risk medication) is important for the patients' outcome ${ }^{26}$. Case 18 with calcium extravasation received surgical intervention and healed after 5 months. The results suggested that the standard protocols of extravasation management in our hospital are appropriate. However, it is still needed to pay attention to improving management through education and training of nurse for the safe administration other than intervention of extravasation ${ }^{27}$.

Our study has some limitations. First, this is a retrospective study with a limited number of patients from a single center. It is possible that our results had residual confounding from uncollected parameters based on medical records. Second, the standard protocols of extravasation management need to be further improved based on big simple size. If available, we would enable a more complete and robust analysis to the risk of the occurrence of extravasation in the future. Nevertheless, our results are noteworthy because the observation of infused high volume/day, received operation, infused agents with high osmolarity and poor vein condition as independent risk factors for 
patients with extravasation warrants further attention.

This study provided important information about the incidence, risk factors and treatment of extravasation in pediatric patients in China. Infused high volume/day, received operation, infused agents with high osmolarity and poor vein condition increased the risk of extravasation. Further prospective research is needed to provide evidence on the role of these risk factors in pediatric patients with extravasation. It is important to nurses and physicians to prevent the occurrence of extravasation through evaluating risk factors. On the other hand, standard protocols of extravasation management should be adopted to prevent further deterioration and complications.

\section{Acknowledgements}

This work was supported by Shanghai Municipal Education Commission-Gaoyuan Nursing Grant Support (no. hlgy16012kyx), Youth Program of Shanghai Nursing Association (2017QNB07), Youth Program of Shanghai Municipal Commission of Health and Family Planning (no. 20134Y090) and Program of Shanghai Shenkang Hospital Development Center (no. SHDC2014616).

The authors sincerely thank Jiangjiang $\mathrm{Xu}$, for guiding in collecting data and statistical analysis.

\section{REFERENCES}

1. Hadaway L. Infiltration and extravasation. Am J Nurs 2007; 107: 64-72.

2. Chiu K, Tindholdt TT, Tonseth KA. Extravasation injuries. Tidsskr Nor Laegeforen 2016; 136: 233-235.

3. Paquette V, McGloin R, Northway T, DeZorzi P, Singh A, Carr R. Describing Intravenous Extravasation in Children (DIVE Study). Can J Hosp Pharm 2011; 64: 340-345.

4. Franck LS, Hummel D, Connell K, Quinn D, Montgomery J. The safety and efficacy of peripheral intravenous catheters in ill neonates. Neonatal Netw 2001; 20: 33-38.

5. Kostogloudis N, Demiri E, Tsimponis A, et al. Severe extravasation injuries in neonates: a report of 34 cases. Pediatr Dermatol 2015; 32: 830-835.

6. Pluschnig U, Haslik W, Bartsch R, Mader RM. Extravasation emergencies: state-of-the-art management and progress in clinical research. Memo 2016; 9: 226230.

7. Goon PK, Dalal M. Limb-threatening extravasation injury: topical negative pressure and limb salvage. Plast Reconstr Surg 2006; 117: 1064-1065.
8. Ghanem AM, Mansour A, Exton R, et al. Childhood extravasation injuries: improved outcome following the introduction of hospital-wide guidelines. J Plast Reconstr Aesthet Surg 2015; 68: 505-518.

9. Sakaida E, Sekine I, Iwasawa S, et al. Incidence, risk factors and treatment outcomes of extravasation of cytotoxic agents in an outpatient chemotherapy clinic. Jpn J Clin Oncol 2014; 44: 168-171.

10. Firat C, Erbatur S, Aytekin AH. Management of extravasation injuries: a retrospective study. J Plast Surg Hand Surg 2013; 47: 60-65.

11. Goutos I, Cogswell LK, Giele H. Extravasation injuries: a review. J Hand Surg Eur Vol 2014; 39: 808-818.

12. Hardie AD, Kereshi B. Incidence of intravenous contrast extravasation: increased risk for patients with deep brachial catheter placement from the emergency department. Emerg Radiol 2014; 21: 235-238.

13. Restieaux M, Maw A, Broadbent R, Jackson P, Barker D, Wheeler B. Neonatal extravasation injury: prevention and management in Australia and New Zealand-a survey of current practice. BMC Pediatr 2013;13: 34.

14. Yan YM, Gong M, Li D, et al. Grade management in establishing pediatric peripheral venous access. Iran J Pediatr 2016; 26: e6321.

15. Alami Z, Nasri S, Ahid S, Kacem HH. Extravasation of contrast medium during CT examination: an observational casecontrol study. Pan Afr Med J 2015; 20: 89.

16. Gilbar PJ, Carrington CV. The incidence of extravasation of vinca alkaloids supplied in syringes or mini-bags. J Oncol Pharm Pract 2006; 12: 113-118.

17. Wang CL, Cohan RH, Ellis JH, Adusumilli S, Dunnick NR. Frequency, management, and outcome of extravasation of nonionic iodinated contrast medium in 69,657 intravenous injections. Radiology 2007; 243: 80-87.

18. Danski MT, Mingorance P, Johann DA, Vayego SA, Lind J. Incidence of local complications and risk factors associated with peripheral intravenous catheter in neonates. Rev Esc Enferm USP 2016; 50: 22-28.

19. Kreidieh FY, Moukadem HA, El Saghir NS. Overview, prevention and management of chemotherapy extravasation. World J Clin Oncol 2016; 7: 87-97.

20. Keidan I, Sidi A, Ben-Menachem E, Derazne E, Berkenstadt $\mathrm{H}$. A simple diagnostic test to confirm correct intravascular placement of peripheral catheters in order to avoid extravasation. J Clin Anesth 2015; 27: $585-588$.

21. Schulmeister L. Extravasation Management: Clinical Update. Semin Oncol Nurs 2011; 27: 82-90.

22. Bellin MF, Jakobsen JA, Tomassin I, et al. Contrast medium extravasation injury: guidelines for prevention and management. Eur Radiol 2002; 12: 2807-2812.

23. Schaverien MV, Evison D, McCulley SJ. Management of large volume CT contrast medium extravasation injury: technical refinement and literature review. J Plast Reconstr Aesthet Surg 2008; 61:562-565. 
24. Fernández-García C, Mata-Peón E, Avanzas-Fernández S. Related factors with extravasation of non-cytostatic agents in peripheral vein catheters. Enferm Clin 2017; 27: 71-78.

25. Sung KY, Lee SY. Nonoperative management of extravasation injuries associated with neonatal parenteral nutrition using multiple punctures and a hydrocolloid dressing. Wounds 2016; 28: 145-151.
26. Yan YM, Fan QL, Li AQ, Chen JL, Dong FF, Gong M. Treatment of cutaneous injuries of neonates induced by drug extravasation with hyaluronidase and hirudoid. Iran J Pediatr 2014; 24:352-358.

27. Coyle CE, Griffie J, Czaplewski LM. Eliminating extravasation events: A multidisciplinary approach. J Infus Nurs 2014; 37: 157-164. 